\title{
Diurnal Variations of Summer Precipitation in the Beijing Area and the Possible Effect of Topography and Urbanization
}

\author{
YIN Shuiqing*1,2,3 (殷水清), LI Weijing ${ }^{3}$ (李维京), Deliang CHEN ${ }^{4}$, \\ Jee-Hoon $\mathrm{JEONG}^{4}$, and GUO Wenli ${ }^{5}$ (郭文利) \\ ${ }^{1}$ State Key Laboratory of Earth Surface Processes and Resource Ecology, \\ Beijing Normal University, Beijing 100875 \\ ${ }^{2}$ School of Geography, Beijing Normal University, Beijing 100875 \\ ${ }^{3}$ Beijing Climate Center, China Meteorological Administration, Beijing 100081 \\ ${ }^{4}$ Department of Earth Sciences, University of Gothenburg, Gothenburg, 40530, Sweden \\ ${ }^{5}$ Beijing Regional Climate Center, Beijing Meteorological Bureau, Beijing 100089
}

(Received 17 March 2010; revised 24 July 2010)

\begin{abstract}
The present study examined the diurnal variations of summer precipitation in the Beijing area by using subdaily precipitation and wind observations. A combined effect of topography and urbanization on the characteristics of diurnal variations was suggested. It was shown that stations located in the plain area exhibited typical night rain peaks, whereas those in the mountainous area exhibited clear afternoon peaks of precipitation diurnal variations. The precipitation peaks were associated with wind fields around the Beijing area, which were found to be highly modulated by mountain-valley circulation and urban-country circulation. The lower-tropospheric wind exhibited a clear diurnal shift in its direction from north at 0800 LST to south at 2000 LST, which reflected mountain-valley circulation. The transitions from valley to mountain wind and the opposite generally happened after sunset and sunrise, respectively, and both occurred earlier for the stations located closer to mountains. By comparing the diurnal variations of precipitation at stations in a northeast suburb, an urban area, and a southwest suburb, it was revealed that the northeast suburb group had the highest normalized rainfall frequency, but the southwest group had the lowest from late afternoon to late evening. On the contrary, in the early morning from about 0200 to 1000 LST, the southwest group and urban group had the highest normalized rainfall frequency. This pattern might originate from the combined effects of mountain-valley topography and urbanization.
\end{abstract}

Key words: diurnal variations, precipitation, mountain-valley circulation, urban effect, Beijing area

Citation: Yin, S. Q., W. J. Li, D. L. Chen, J.-H. Jeong, and W. L. Guo, 2011: Diurnal variations of summer precipitation in the Beijing area and the possible effect of topography and urbanization. Adv. Atmos. Sci., 28(4), 725-734, doi: 10.1007/s00376-010-9240-y.

\section{Introduction}

The diurnal variation of precipitation is one of the fundamental characteristics of weather and the climate system. Basically arising from diurnal variation of solar radiation and affected by dynamical backgrounds from very local to large-scale, a precipitation event tends to happen during a specific period of time in a day. In spite of the fact that much research has been done in recent decades, the ability of climate models to simulate diurnal variations of precipitation still needs to be improved. Therefore, more and more research focuses on the diurnal variations of precipitation, because it is acknowledged as one of the representative

\footnotetext{
*Corresponding author: YIN Shuiqing, yinshuiqing@bnu.edu.cn

(C) China National Committee for International Association of Meteorology and Atmospheric Sciences (IAMAS), Institute of Atmospheric Physics (IAP) and Science Press and Springer-Verlag Berlin Heidelberg 2011
} 
features required to diagnose local climate systems and to verify the performance of climate models (Zhou et al., 2008).

Previous research showed that for the warm season (May to September), nocturnal (2000-0800 LST) precipitation predominated over the Tibetan Plateau, Southwest China, and Northwest China, whereas daytime (0800-2000 LST) precipitation predominated over Northeast China and Southeast China ( $\mathrm{Yu}$ et al., 2007a; Yin et al., 2009). An early morning peak is distinct in central eastern China, which is mainly caused by frequent precipitation occurrences of relatively long duration ( $\mathrm{Yu}$ et al., 2007b). This morning peak tends to be strengthened (weakened) along with the advancement (retreat) of the East Asian monsoon trough (Yin et al., 2009). Research on the diurnal variations of precipitation over southeastern China further revealed the mechanism of an enhanced early morning peak associated with the diurnal variation of monsoon activity (Chen et al., 2009a, 2009b). Additionally, cloud radiative forcing was suggested as one of the primary factors in modulating the diurnal cycle of rainfall when the diurnal cycle in the southwestern and southeastern parts of southern contiguous China were compared (Li et al., 2008a). Diurnal variations of surface flow over central eastern China were also revealed, and the contribution of the diurnal surface wind to the diurnal feature of precipitation was previously discussed (Yu et al., 2009; Chen et al., 2010). Furthermore, it was found that diurnal variations exhibited long-term change (Fujibe et al., 2006). For example, hourly precipitation records during 1961-2004 from the Beijing Nanjiao observatory station indicated that convective rainfall events of relatively short duration in the afternoon and early evening increased while relatively long duration events during the night and early morning decreased remarkably in forty recent years ( $\mathrm{Li}$ et al., 2008b). The afternoon peak caused by convective precipitation was believed to be enhanced by the intensification of the urban heat island (Fujibe et al., 2006).

Beijing is situated at the northwestern part of the North China Plain, surrounded by mountains to the north, northwest, and west of the area (see Fig. 1). Therefore, it has been recognized that mountain-valley circulation significantly influences the local climate in the region around Beijing ( $\mathrm{Hu}$ et al., 2005; Sun, 2005; Li and Shu, 2008; Wang et al., 2008a). Associated with the diurnal variation of precipitation, Wu (1993) suggested that the precipitation in the mountainous area of Beijing, Tianjin, and Hebei Province exhibited a clear afternoon peak from convective precipitation, whereas that in the plain area exhibited a nighttime peak (Wu, 1993). Lin (1995) made a general conclu-

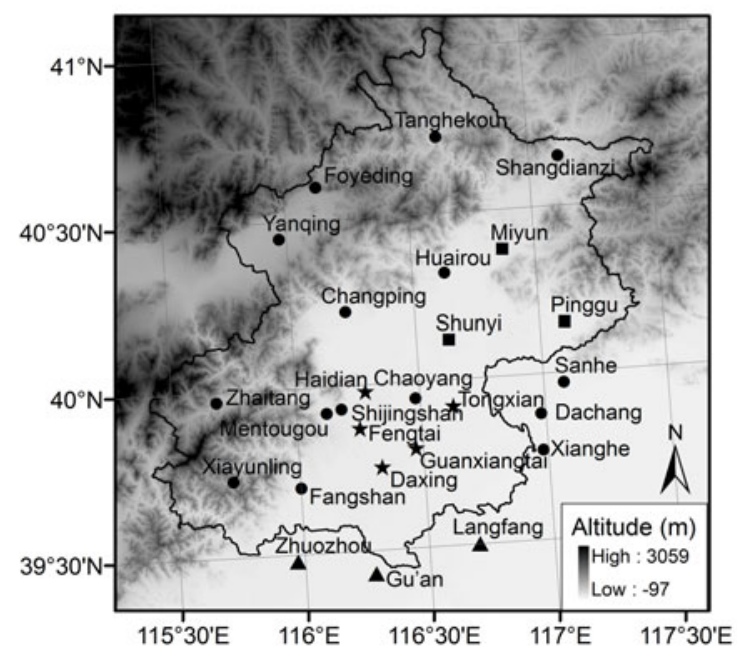

Fig. 1. Stations with hourly precipitation and six-hourly surface wind data in this study. Squares stand for the stations in Northeast group, stars for those in Urban area and triangles for those in Southwest group.

sion that stations in convex topography were prone to have more precipitation in the daytime, whereas those with concave topography have more nocturnal precipitation. The mountain-valley circulation around Beijing and its mechanism have been well described. In addition, Beijing is one of the most urbanized regions in the world, and more than 15 million people reside in the urban plain area, so it has been suggested that the urban heat island effect is also likely to have an influence on the diurnal variations of precipitation around the Beijing area. Sun and Yang (2008) showed that most mesoscale torrential rain processes induced by the combined influence of topography and urban circulation easily occurred in front of mountains in the evening or in the early morning. The amount and frequency of rainfall tends to be larger in urban centers and downwind areas than in the surrounding areas, especially for relatively intense convective rainfall in summer (Collier, 2006; Zheng and Liu, 2008) This effect, however, is not confirmed in the Beijing area in the existing literature by Sun and Shu (2007) and Wang et al. (2008b). One possibility is that the indicators for seasonal rainfall amount and rainfall days used in these two studies may be not sensitive indices for convective rainfall processes.

The objectives of this research were to investigate: (1) diurnal variations of precipitation in Beijing and its adjacent area based on hourly precipitation data in summer from 26 stations; (2) mountain-valley circulation using lower- and upper-level National Centers for Environmental Prediction (NCEP) final analysis wind 
data and in situ surface observation wind data; (3) urban effects on rainfall using hourly precipitation as the indicator; and (4) possible effects of mountain-valley topography and urban effects on diurnal variations of precipitation.

\section{Data and method}

Hourly precipitation data from 1990 to 2007 from 26 automatic weather stations, of which 20 stations were located in the Beijing municipality and the other six belonged to neighboring Hebei Province (Fig. 1, Tables 1 and 2), were utilized. About $72.5 \%$ of annual precipitation occurs in summer (June-July-August, JJA in short) in the Beijing area due to the East Asian monsoon (Wang et al., 2008c), so only data in summer were analyzed in this study. The data loss rate, which was defined as percent of hours without observation dividing by total hours during 1990-2007, ranged from $0.5 \%$ to $24.5 \%$ with an average of $9.4 \%$. Diurnal variations of precipitation can be characterized by the frequency, amount, and intensity of precipitation (Zhou et al., 2008). Present study utilized the diurnal vari- ation of precipitation frequency. Our previous study (Yin et al., 2009) suggested that diurnal patterns of precipitation frequency and amount were quite similar except that the afternoon maximum of precipitation amount was relatively higher due to intense convective precipitation in the afternoon. The frequency of hourly precipitation was defined as the number of rainfall hours divided by the total observation hours by using Eqs. (1) and (2). To facilitate the comparisons among stations in suburban and urban areas, the hourly occurrences were normalized by dividing them by the 24-h means following Yin et al. (2009) [Eq. (3)].

$$
\begin{gathered}
f_{n}=\frac{\sum_{d=1}^{D} c_{d, n}}{D} \\
c_{d, n}= \begin{cases}0, & p_{d, n}<0.1 \\
1, & p_{d, n} \geqslant 0.1\end{cases} \\
F_{\mathrm{N}, n}=\frac{24 f_{n}}{\sum_{n=1}^{24} f_{n}}
\end{gathered}
$$

\begin{tabular}{|c|c|c|c|c|c|c|c|}
\hline Station No. & Station Name & $\begin{array}{l}\text { Latitude } \\
\left({ }^{\circ} \mathrm{N}\right)\end{array}$ & $\begin{array}{l}\text { Longitude } \\
\qquad\left({ }^{\circ} \mathrm{E}\right)\end{array}$ & $\begin{array}{l}\text { Altitude } \\
\quad(\mathrm{m})\end{array}$ & $\begin{array}{l}\text { Percent of } \\
\text { hours without } \\
\text { observation } \\
(\%)\end{array}$ & $\begin{array}{c}\text { Annual average } \\
\text { during } 1971-2000 \\
(\mathrm{~mm})\end{array}$ & $\begin{array}{l}\text { Percentage } \\
\text { of night rain } \\
(\%)\end{array}$ \\
\hline 54399 & Haidian & 39.98 & 116.28 & 46.3 & 12.6 & 582.3 & 53.3 \\
\hline 54433 & Chaoyang & 39.95 & 116.48 & 36.5 & 9.7 & 581.7 & 55.7 \\
\hline 54511 & Guanxiangtai & 39.80 & 116.47 & 32 & 14.7 & 571.9 & 57.2 \\
\hline 54514 & Fengtai & 39.87 & 116.25 & 56.3 & 6.9 & 567.0 & 53.9 \\
\hline 54398 & Shunyi & 40.12 & 116.63 & 39.5 & 15.8 & 603.2 & 54.8 \\
\hline 54412 & Tanghekou & 40.73 & 116.63 & 333.7 & 24.0 & 485.1 & 44.9 \\
\hline 54416 & Miyun & 40.38 & 116.87 & 73.1 & 24.5 & 638.7 & 55.7 \\
\hline 54419 & Huairou & 40.32 & 116.63 & 60.6 & 7.5 & 670.2 & 51.9 \\
\hline 54421 & Shangdianzi & 40.65 & 117.12 & 286.5 & 22.1 & 627.6 & 54.2 \\
\hline 54424 & Pinggu & 40.15 & 117.10 & 29.4 & 11.6 & 641.1 & 54.3 \\
\hline 54431 & Tongxian & 39.92 & 116.63 & 26.9 & 9.2 & 562.0 & 57.5 \\
\hline 54594 & Daxing & 39.75 & 116.33 & 41.3 & 7.4 & 552.6 & 55.8 \\
\hline 54501 & Zhaitang & 39.97 & 115.68 & 441.1 & 4.5 & 464.2 & 43.6 \\
\hline 54505 & Mentougou & 39.92 & 116.12 & 93.6 & 9.5 & 601.4 & 54.9 \\
\hline 54596 & Fangshan & 39.70 & 116.00 & 48.9 & 1.9 & 582.8 & 56.0 \\
\hline 54597 & Xiayunling & 39.73 & 115.73 & 409.1 & 24.2 & 640.6 & 54.7 \\
\hline 54406 & Yanqing & 40.45 & 115.97 & 489 & 8.6 & 441.8 & 45.0 \\
\hline 54499 & Changping & 40.22 & 116.22 & 79.7 & 6.2 & 542.9 & 49.5 \\
\hline 54410 & Foyeding & 40.60 & 116.13 & 1216.9 & 3.8 & 535.5 & 45.9 \\
\hline 54513 & Shijingshan & 39.93 & 116.18 & 70.8 & 11.1 & 558.0 & 54.1 \\
\hline 54502 & Zhuozhou & 39.48 & 115.97 & 36.5 & 0.5 & 563.8 & 56.1 \\
\hline 54510 & Dachang & 39.88 & 116.98 & 16.5 & 1.6 & 590.6 & 50.9 \\
\hline 54512 & Gu'an & 39.43 & 116.28 & 23.8 & 0.8 & 548.2 & 54.9 \\
\hline 54515 & Langfang & 39.50 & 116.70 & 14.3 & 2.0 & 555.3 & 55.2 \\
\hline 54520 & Sanhe & 39.97 & 117.08 & 19.4 & 1.5 & 607.2 & 53.0 \\
\hline 54521 & Xianghe & 39.77 & 116.98 & 13.5 & 2.4 & 580.8 & 50.7 \\
\hline
\end{tabular}

Table 1. Information on the stations analyzed in the study. 
Table 2. Information on precipitation and wind data used in the study.

\begin{tabular}{ccc}
\hline Data type & Number of stations & Length of series \\
\hline Hourly precipitation data & 26 & JJA, $1990-2007$ \\
Six-hourly wind data & 26 & JJA, 1990-2007 \\
Hourly wind data & 20 & JJA, 2005-2007 \\
NCEP final analysis data & $38^{\circ}-43^{\circ} \mathrm{N}, 113^{\circ}-119^{\circ} \mathrm{E}$ & $\mathrm{JJA}, 2000-2007$ \\
\hline
\end{tabular}

In Eqs. (1)-(3), $n$ is the LST expressed in hours, $d$ is the number of observation days, $f_{n}$ is the frequency of precipitation, $c_{d, n}$ is a counter (units: $\mathrm{mm} \mathrm{h}^{-1}$ ), $p_{d, n}$ is the hourly precipitation amount, and $F_{\mathrm{N}, n}$ is the normalized precipitation frequency.

Six-hourly zonal and meridional wind, from the NCEP final analysis of $1^{\circ} \times 1^{\circ}$ spatial resolution data, in summer (June to August) from 2000 to 2007 were analyzed to show the characteristics of lower- and upper-level wind profiles (Table 2). Six-hourly in situ observations of wind speed and wind direction from 1990 to 2007 for 26 stations were also analyzed to reveal surface wind fields (Table 2). Hourly wind data from 2005 to 2007 for 20 stations (selected by the criteria with data loss less than 1\%) were also collected to detect diurnal variations of wind (Table 2).

\section{Results and Discussion}

\subsection{Diurnal variations of precipitation}

First, the general feature of diurnal variations of precipitation in the regions around the Beijing area was examined in Fig. 2. Overall, most stations had more precipitation in the nighttime $(2000-0800$ LST) than in the daytime (0800-2000 LST) except for several stations located in the foot of the western and northwestern mountainous areas: Zhaitang, Tanghekou, Yanqing, Foyeding (the percentages of night rain for these stations were $43.6 \%, 44.9 \%, 45 \%$, $45.9 \%$ and $49.5 \%$, respectively, see Table 1$)$. In particular, diurnal patterns of precipitation frequency at Zhaitang, Tanghekou, and Yanqing showed clear afternoon and early morning peaks (Fig. 2a). These three
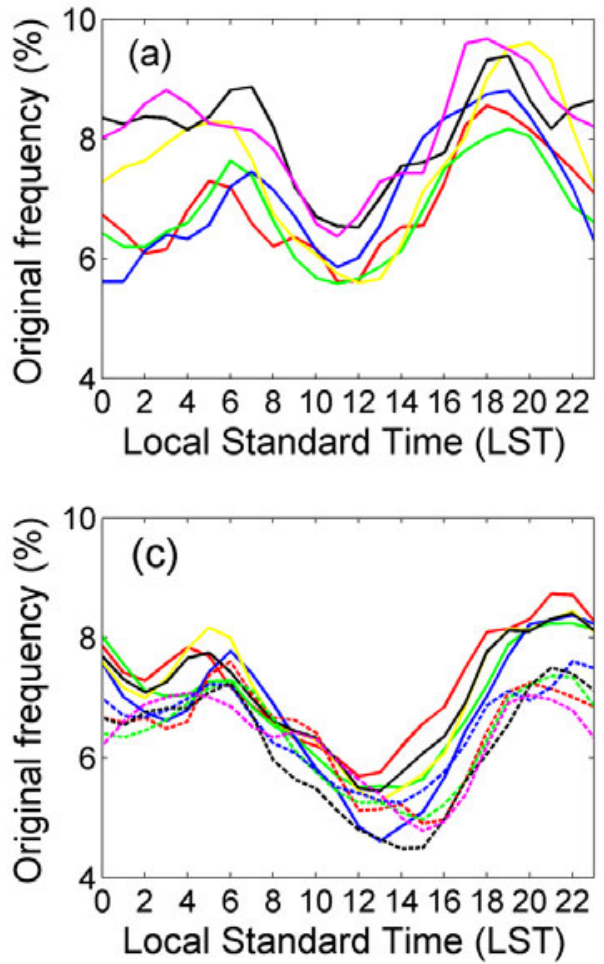
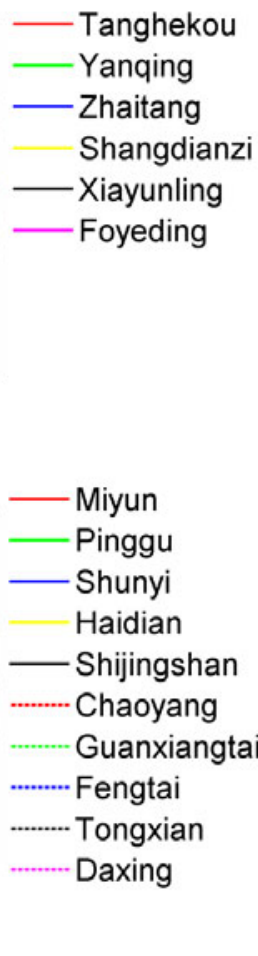
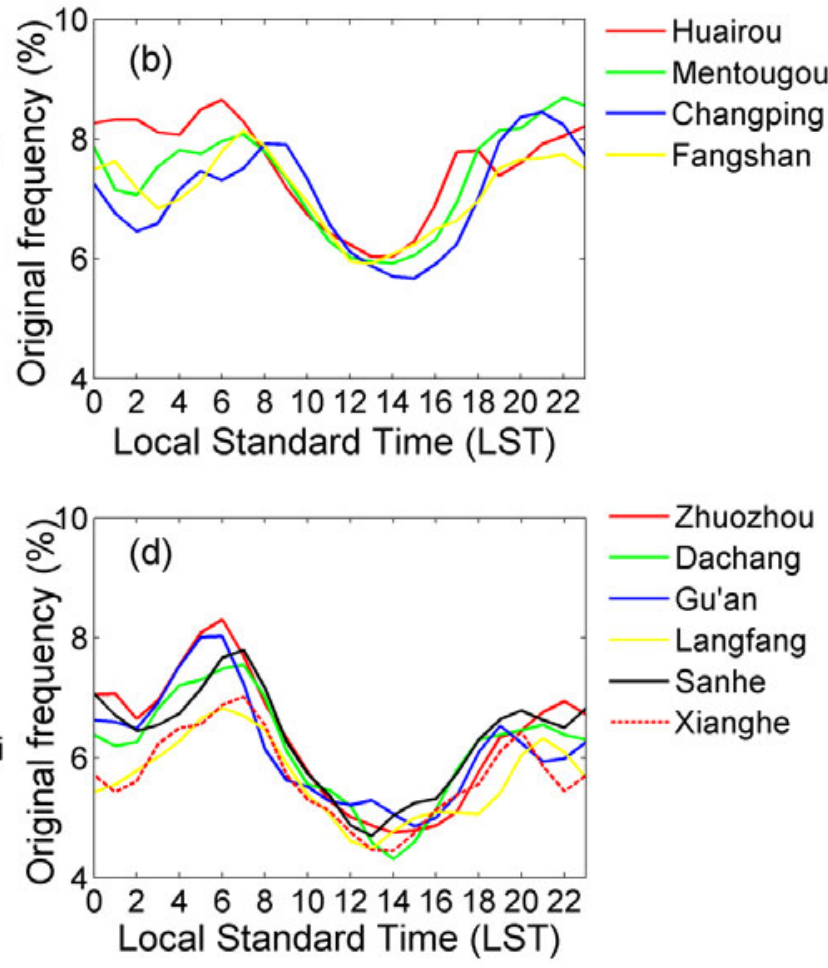

Fig. 2. Diurnal variations of precipitation frequency in summer for 26 stations in Beijing and its surrounding area: (a) six stations in the mountainous area; (b) four stations close to mountainous area; (c) ten stations in the plain in Beijing municipality; (d) six stations in the plain in Hebei province close to southeastern part of Beijing municipality. 

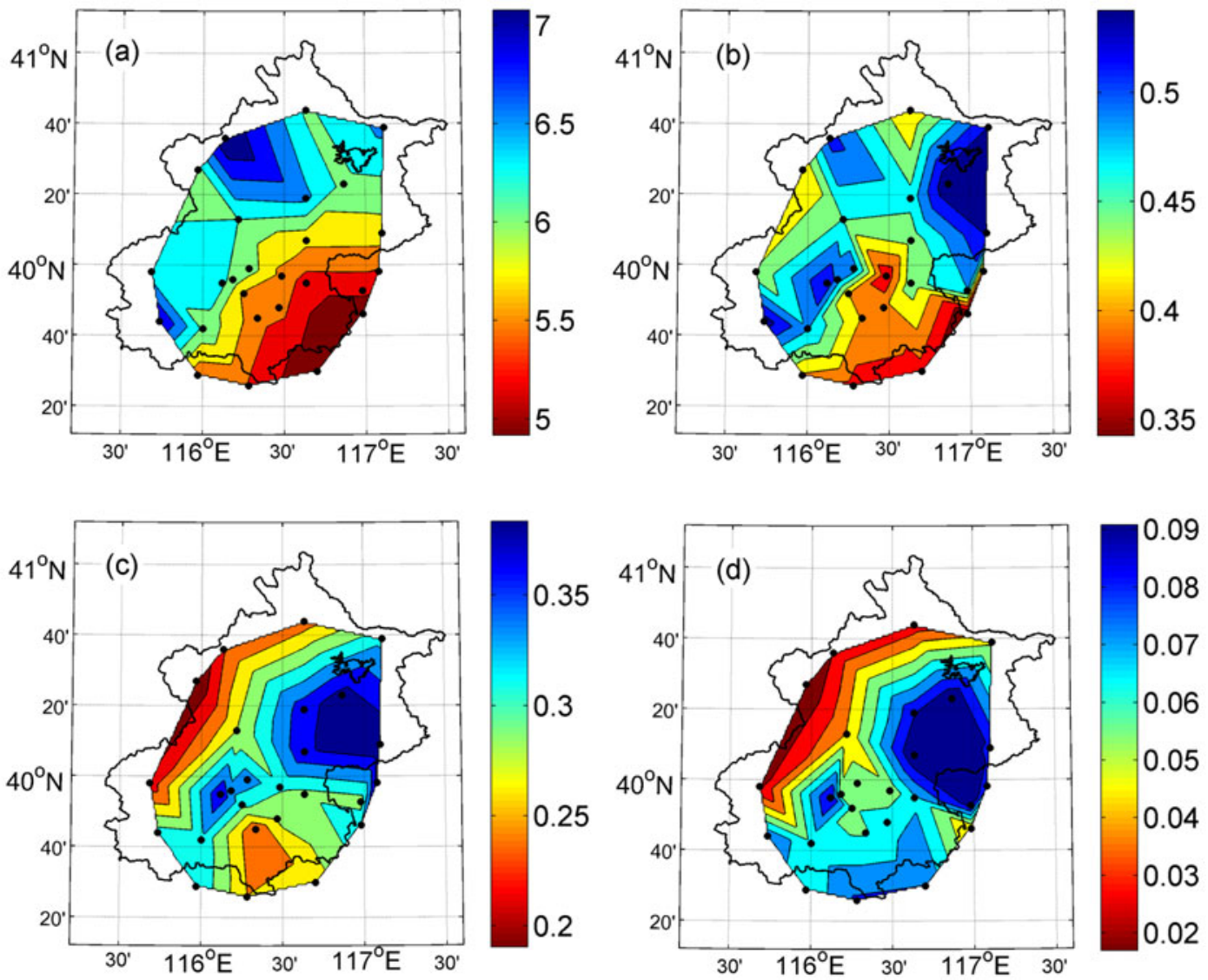

Fig. 3. Spatial distribution of hourly precipitation occurring frequency (\%) grouped by intensity: (a) $0-5 \mathrm{~mm} \mathrm{~h}^{-1}$; (b) $5-10 \mathrm{~mm} \mathrm{~h}^{-1}$; (c) $10-25 \mathrm{~mm} \mathrm{~h}^{-1}$; (d) over $25 \mathrm{~mm} \mathrm{~h}^{-1}$.

stations were located on the lee slope of the western and northern mountainous areas where the annual precipitation was relatively lower compared with other stations (Table 1). The other three stations in Fig. 2a, Shangdianzi, Xiayunling, and Foyeding, were also located in the western and northern mountainous areas, but their precipitation frequencies were generally higher, especially for the period from late night to early morning. The diurnal patterns of these six stations seem to be attributed to their local topography. They are located in the mountainous areas, where the surface is easily heated by incoming solar radiation during the daytime, and this may induce convective precipitation in the afternoon more frequently.

Diurnal patterns of precipitation frequency for the remaining 20 stations located in the plain area (Figs. 2b, c, and d) exhibited high probability from 1800 LST to 0600 LST. Most of these 20 stations in Beijing and its adjacent area also exhibited an afternoon peak at about 1800-1900 LST and an early morning peak at 0600 LST. However, neither peak was very obvious due to relatively continuous higher rainfall probability during the nighttime. There were still some small dif- ferences among the stations in the plain area. First, the stations close to the piedmont windward slopes tend to have relatively higher precipitation frequency in the daytime. Second, for stations in the northeastern part of the Beijing Plain, the frequency from 1800 to $0200 \mathrm{LST}$ tends to be higher (Fig. 2c), which is more clearly seen in the spatial distribution of hourly precipitation frequency (Fig. 3). The frequency distribution of hourly precipitation less than $5 \mathrm{~mm} \mathrm{~h}^{-1}$, which is defined as the rainfall hours with intensity less than $5 \mathrm{~mm} \mathrm{~h}^{-1}$ dividing by total hours with observations, exhibits a high value in the areas close to piedmont windward slopes from southwest to northeast (Fig. 3a), while the high probability values of hourly precipitation over $5 \mathrm{~mm} \mathrm{~h}^{-1}$ tends to move to the northeastern part of the Beijing Plain (Figs. 3b, $\mathrm{c}$, and $\mathrm{d}$ ). The possible reason for this pattern will be discussed in the next section.

\subsection{Related circulation}

From the wind profile based on the NCEP final analysis data, it was demonstrated that the tropospheric circulation around Beijing exhibits a diurnal 
(a)

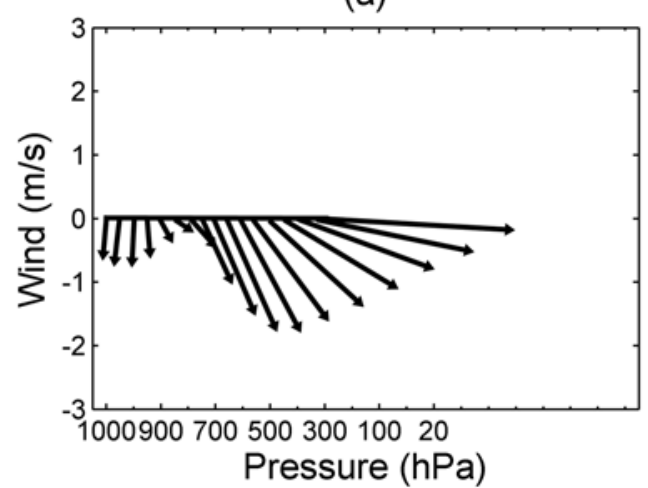

(c)

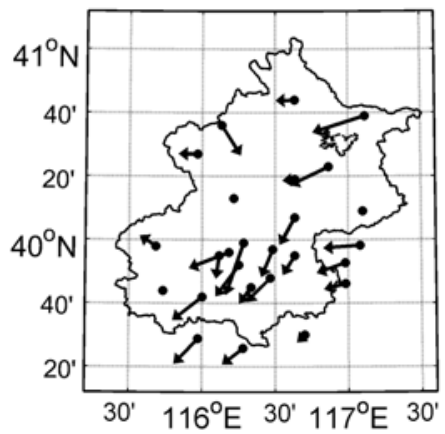

(b)

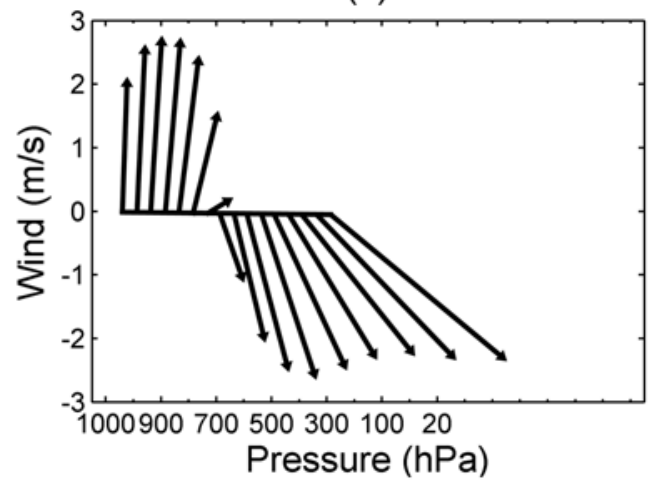

(d)

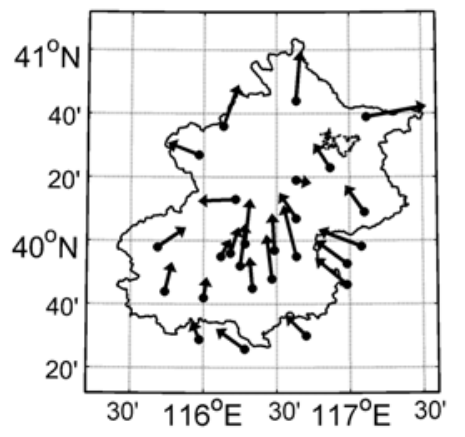

Fig. 4. Wind profile using NCEP final analysis data averaged over grids $\left(40^{\circ} \mathrm{N}, 116^{\circ} \mathrm{E}\right)$ and $\left(40^{\circ} \mathrm{N}, 117^{\circ} \mathrm{E}\right)$ and surface wind field using six-hourly in situ observation wind data in JJA: (a) wind profile at $0800 \mathrm{LST}$; (b) wind profile at $2000 \mathrm{LST}$; (c) surface wind field at 0800 LST; (d) surface wind field at $2000 \mathrm{LST}$. The heights are $1000 \mathrm{hPa}, 975 \mathrm{hPa}, 950 \mathrm{hPa}, 925$ $\mathrm{hPa}, 900 \mathrm{hPa}, 850 \mathrm{hPa}, 800 \mathrm{hPa}, 750 \mathrm{hPa}, 700 \mathrm{hPa}, 650 \mathrm{hPa}, 600 \mathrm{hPa}, 550 \mathrm{hPa}, 500 \mathrm{hPa}$, $450 \mathrm{hPa}, 400 \mathrm{hPa}, 350 \mathrm{hPa}, 300 \mathrm{hPa}$ for horizonal axes for (a) and (b). The length of lines denotes vector wind speed and the arrows denote the direction which the wind blowing to.

reversal of wind direction, which may be related to the mountain-valley circulation (Figs. 4a, b). At 0800 LST, wind in the lower troposphere was northerly (Fig. 4a), while it was strongly southerly at 2000 LST (Fig. 4b). Recalling that the mountainous regions are located to the north and northwest of Beijing, the northerly wind at 0800 LST and southerly wind at 2000 LST seem to represent the so-called down-valley and up-valley wind, respectively. The reversal of wind direction is confined in the lower troposphere, from the surface up to the $800 \mathrm{hPa}$ level. In the upper level, strong westerly or northwesterly wind prevails both at 0800 LST and at 2000 LST.

This reversal of wind direction is also confirmed by the in situ surface wind observation for the 26 stations during 1990-2007. The wind directions for most stations are opposite between 0800 LST and 2000 LST (Figs. 4c, d). At 0800 LST, surface wind tends to be from the northern and western mountainous areas, while at $2000 \mathrm{LST}$, surface wind is from the southern valley area. At $0200 \mathrm{LST}$ and $1400 \mathrm{LST}$, wind directions are not so homogeneous, but it seems that wind directions point to the city center, which may be attributed to urban-country circulation (figures not shown). Furthermore, additional details of diurnal variations of surface wind are examined based on hourly wind data. It is found that the transition time from the up-valley wind to down-valley wind after sunset is quite different among stations, as is that from down-valley wind to up-valley wind after sunrise. The transition time is earlier for the stations closer to mountains as shown in Fig. 5. For Shangdianzi, Miyun, Shunyi, Zhuozhou, and Gu'an (Figs. 5a, $\mathrm{b}, \mathrm{c}, \mathrm{e}, \mathrm{f})$, the transition time from southerly wind to northerly wind is about 1900, 2000, 2300, 0100, and 0200 LST respectively; that from northerly wind to southerly wind is about $0800,1100,1100,1100$, and 1200 LST, respectively. The wind direction does not change until 0700 LST for Daxing (Fig. 5d), which is possibly attributed to urban-country circulation. Daxing is located to the south of the urban area, where the country wind in the night points to the city center from 

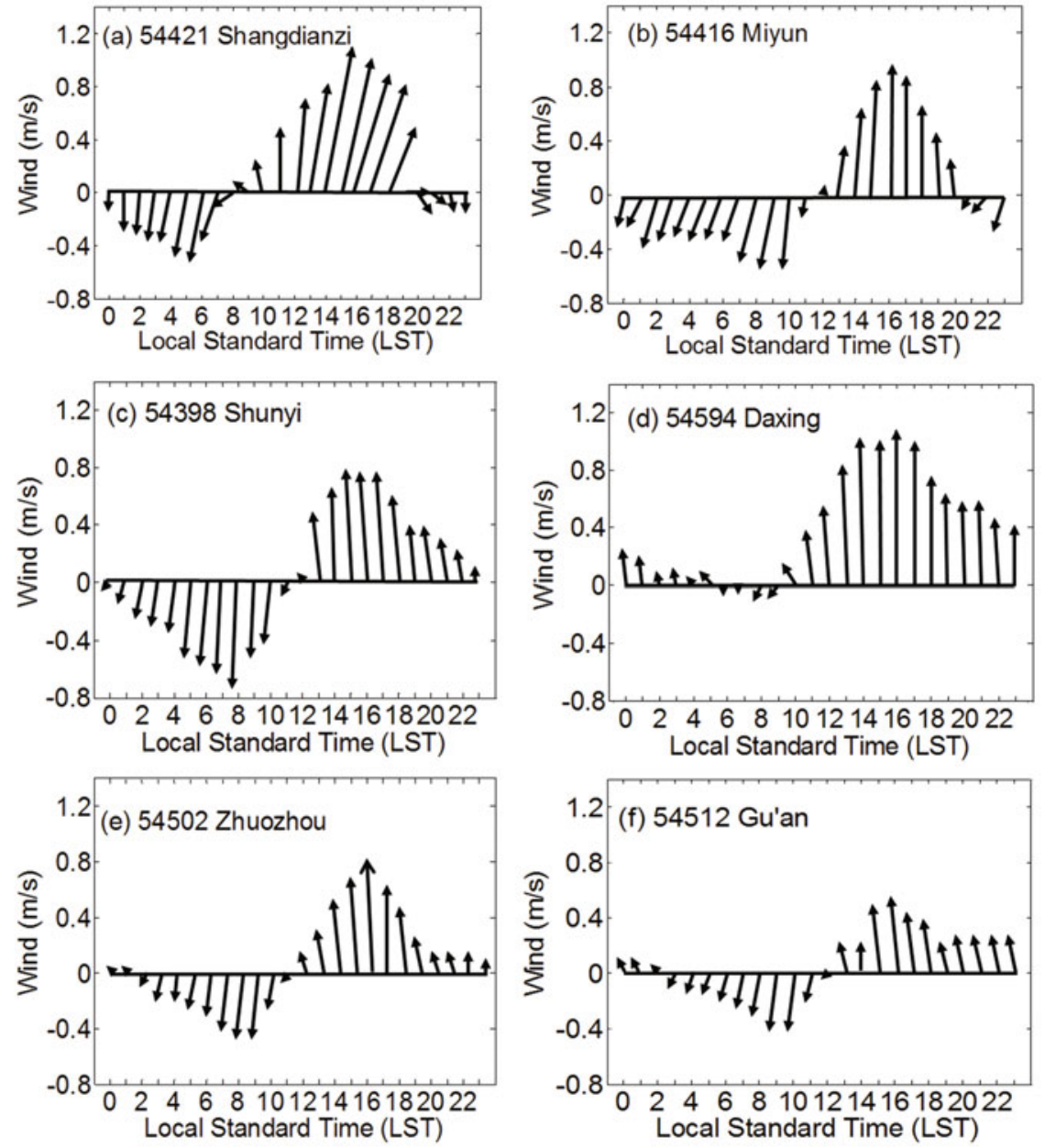

Fig. 5. Diurnal variations of wind for 6 stations: (a) Shangdianzi; (b) Miyun; (c) Shunyi; (d) Daxing; (e) Zhuozhou and (f) Gu'an. The length of lines denotes vector wind speed and the arrows denote the direction which the wind blowing to.

the south.

\subsection{Possible effects of mountain-valley circu- lation and urbanization}

As suggested by the diurnal variations of surface wind around the Beijing area, the urban and country winds may affect diurnal changes in local circulation and further affect precipitation. To detect the urban effect on diurnal variations of precipitation in Beijing, eleven representative stations in the plain area are grouped into three regions which represent the southwest suburbs, the urban area, and the northeast suburbs (Fig. 1). The southwest suburb group includes Zhuozhou, Gu'an, and Langfang; the urban group includes Haidian, Fengtai, Tongxian, Guanxiangtai, and Daxing; and the northeast suburb group includes Miyun, Pinggu, and Shunyi (see Fig. 1). These stations are selected because they are relatively far from mountainous areas. Note that Chaoyang station is not selected because it is surrounded by trees and cannot represent the urban climate anymore (Wang and $\mathrm{Hu}$, 2006). Huairou station is not selected because its location has been changed since 1996 and the temperature shows a decreasing trend since 1990, which is not consistent with the increasing trend of other stations in the Beijing Plain. Overall, from late afternoon to late evening, the normalized frequency for the northeast group exhibits the highest probability and that for the southwest group exhibits the lowest. On the contrary, in the morning from about 0200 to 1000 LST, the southwest group and urban group show higher normalized probability than the northeast group (Fig. 6). Figure 6 supports that the differences among three groups are quite obvious during 1900-2300 LST and 0400-0800 LST.

The higher occurrence of nighttime rain in Beijing is presumed to be mainly attributed to mountainvalley circulation. Insummer, southerly and southeast- 


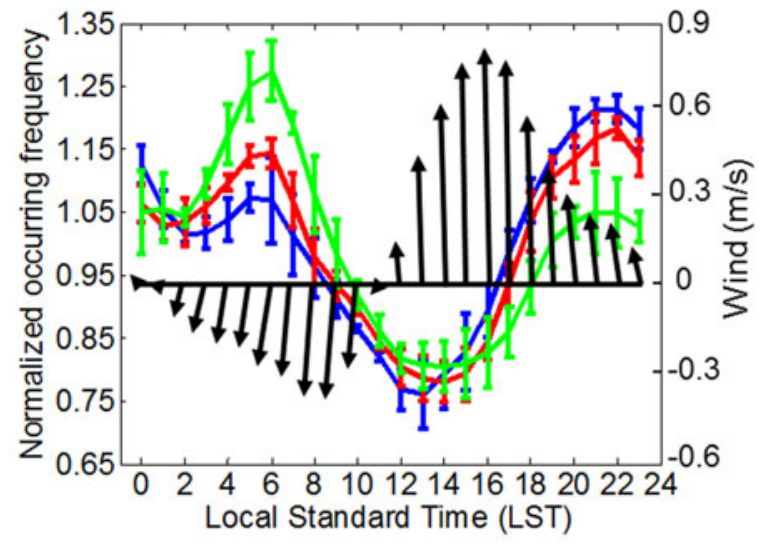

Fig. 6. Diurnal variations of normalized precipitation occurring frequency for three groups of station in the northeast (blue line), urban area (red line) and southwest (green line) respectively and diurnal variation of wind for these stations (black line). The solid blue, red and green lines stand for the values averaged over stations in the same group; The error bars stand for the standard deviation among stations in the same group; The length of black lines denotes vector wind speed and the arrows denote the direction which the wind blowing to. Northeast group includes Miyun, Pinggu, and Shunyi; urban group includes Haidian, Fengtai, Tongxian, Guanxiangtai and Daxing; and southwest group includes Zhuozhou, Gu'an and Langfang.

erly winds originating from the prevailing East Asian monsoon circulation supply a lot of moisture for precipitation, which seems to be one of the prerequisites. In the afternoon, the divergence at the $950 \mathrm{hPa}$ level is negative in the western and northern mountainous areas, which indicates that upward motions are developing and coincident with the afternoon peak of diurnal precipitation variations in this area. At the same time, the downward motion leads to a low probability of precipitation over the plain (Figs. 7a, b). After sunset, wind becomes mountainous, and, thus, relatively cool air from mountainous rural areas converges in the warmer plain urban areas (Fig. 7c), possibly causing the nocturnal precipitation maximum in the plain, similarly suggested by Jiang and Liu (2007). At 0800 LST, the convergence remains over the plain but is substantially weakened (Fig. 7d).

Also, diurnal variations of precipitation in the Beijing area show some modulation from the urbanization effect. The urban heat island is known to increase the thermal difference between mountains and plains (Lin and $\mathrm{Yu}, 2005$ ), which may further enhance the so-called Mountain-Plains Solenoid (MPS). From $1400 \mathrm{LST}$ to $0200 \mathrm{LST}$, the northeast group shows the highest normalized precipitation probability, while the southwest group shows the lowest, but the opposite situation is found from 0200 LST to 1400 LST (Fig. 6). This pattern may be attributed to the combined effects of mountain-valley topography and urbanization. Namely, in the afternoon, when the surface wind is from south, the probability of rainfall in the urban center and downwind area (northeast suburbs now) increase (Fig. 6). On the contrary, in the early evening around 2000 LST, when valley wind begins to change to mountainous wind for stations in the northeastern part of the Beijing Plain, resulting winds from the west, northwest, and northeast begin to converge in the plain. Thus the northeastern area, where Miyun, Shunyi, and Pinggu are located, can likely be the convergence point, where it is easily to trigger precipitation. The convective rain triggered by the convergence of cool mountainous winds and the warm urban atmosphere seems to induce heavy rain intensity in the northeastern part of the Beijing Plain, where the hourly precipitation with an intensity higher than $5 \mathrm{~mm} \mathrm{~h}^{-1}$ exhibits highest frequency. As the wind direction begins to change in the urban area and southwest suburb after 0100 LST, the corresponding precipitation probabilities in these areas also increase rapidly. Therefore, the normalized frequency of rainfall in the urban and downwind area (southwest suburbs now) is found to be higher than that in the northeast area in the early morning during 0400-0800 LST. This transition of the highest normalized precipitation probability within a day (from the northeast area in the afternoon and evening to the southwest area in the morning) may induce insignificant differences between upwind and downwind areas if the indicator is daily or seasonal precipitation as shown in studies by Sun and Shu (2007) and Wang et al. (2008b).

\section{Conclusion}

The present study has investigated detailed characteristics of the diurnal variation of precipitation in Beijing and suggested possible influences from localized circulation characteristics induced by mountainvalley topography and urbanization effects. The spatial variations of precipitation are generally influenced by large-scale systems, local topography, and LUCC (land-use and land-cover change). The effect of largescale systems on precipitation distribution could be generally regarded as the same within a city scope. The difficulty is how to distinguish and separate the effect of topography from urban effects on diurnal variations of precipitation, which is necessary when the effects of human activities on climate change are to be evaluated. We will further explore this by using a longer series of hourly data and utilizing mesoscale 
(a) 0600 UTC (1400 LST)

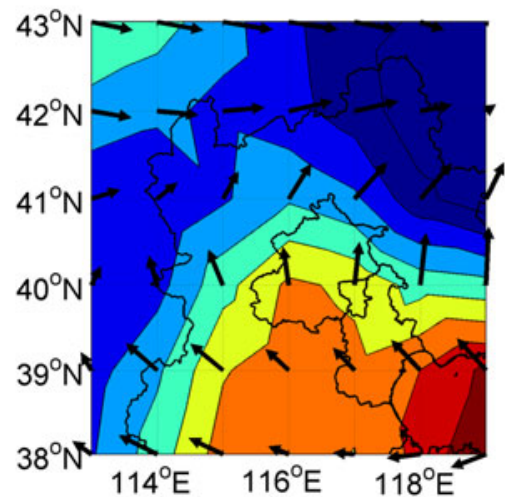

(c) 2000 UTC (0200 LST)

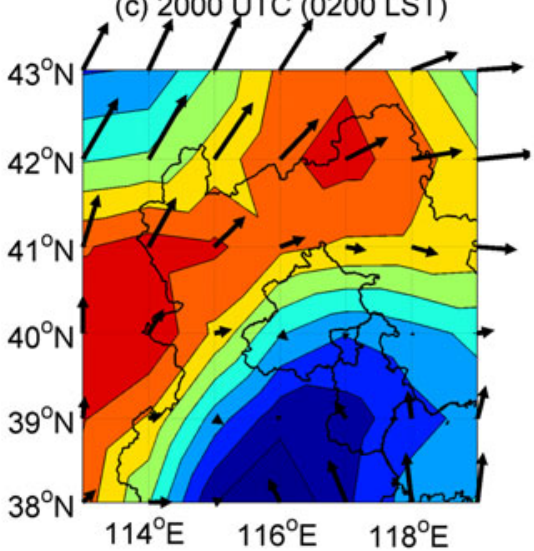

(b) 1200 UTC (2000 LST)

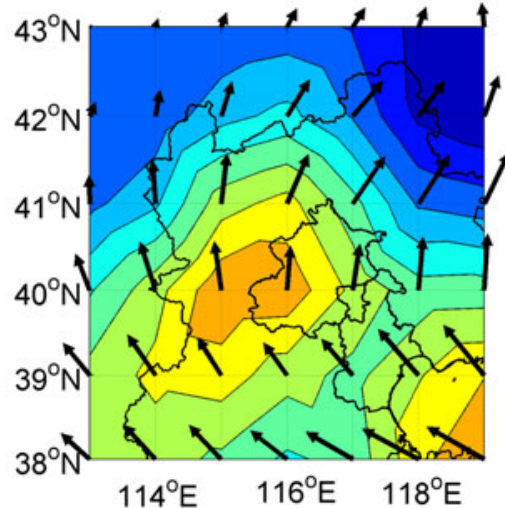

(d) 2400 UTC (0800 LST)

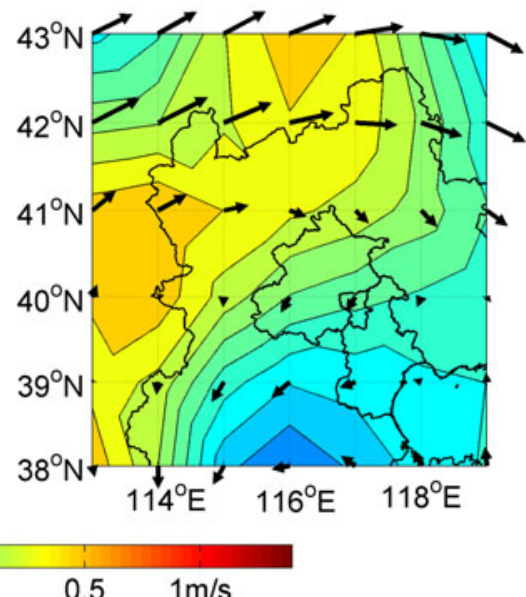

Fig. 7. Spatial distribution of the $950 \mathrm{hPa}$ divergence (colored) and wind vectors based on the NCEP final analysis data in JJA during 2000-2007 at (a) $1400 \mathrm{LST}$, (b) $2000 \mathrm{LST}$, (c) $0200 \mathrm{LST}$ and (d) $0800 \mathrm{LST}$.

model experiments. The study may be useful for refining short-range precipitation forecasts and, further, be a benefit for urban drainage system planning and water resources protection in the Beijing area.

Acknowledgements. The authors would like to thank the Hebei Meteorological Bureau for supplying surface wind and precipitation data and two anonymous reviewers for their valuable comments. NCEP final analysis data for this study are from the Research Data Archive (RDA), which is maintained by the Computational and Information Systems Laboratory (CISL) at the National Center for Atmospheric Research (NCAR). NCAR is sponsored by the National Science Foundation (NSF). The original data are available from the RDA (http://dss.ucar.edu) in dataset number ds083.2. This research is supported by grants from the National Basic Key Research Program (973) under Grant No. 2006CB403606, the National Key Technology R\&D Program under Grant No. 2007BAC29B04, and the National Science Foundation
Project for Post-doctoral Scientists of China under Grant No. 20080440343.

\section{REFERENCES}

Chen, G., W. M. Sha, and T. Iwasaki, 2009a: Diurnal variation of precipitation over southeastern China: Spatial distribution and its seasonality. J. Geophys. Res., 114, D13103, doi: 10.1029/2008JD011103.

Chen, G., W. M. Sha, and T. Iwasaki, 2009b: Diurnal variation of precipitation over southeastern China: 2. Impact of the diurnal monsoon variability. J. Geophys. Res., 114, D21105, doi: 10.1029/2009JD012181.

Chen, H. M., R. C. Yu, J. Li, W. H. Yuan, and T. J. Zhou, 2010: Why nocturnal long-duration rainfall presents an eastward delayed diurnal phase along the Yangtze River. J. Climate, 23(4), 905-917, doi: 10.1175/2009JCLI3187.1.

Collier, C. G., 2006: The impact of urban areas on weather. Quart. J. Roy. Meteor. Soc., 132(614), 125 
Fujibe, F., N. Yamazaki, and K. Kobayashi, 2006: Longterm changes in the diurnal precipitation cycles in Japan for 106 years (1898-2003). J. Meteor. Soc. Japan, 84(2), 311-317.

Hu, X. M., S. H. Liu, F. M. Liang, J. H. Wang, H. P. Liu, Y. C. Wang, and J. Li., 2005: Observational study of wind fields, temperature fields over Beijing area in summer and winter. Acta Scientiarum Naturalium, Universitatis Pekinensis, 41(3), 399-407.

Jiang, X. Y., and W. D. Liu, 2007: Numerical simulation on impacts of urbanization on heavy rain in Beijing using different land use data. Acta Meteorologica Sinica, 21(2), 245-255.

Li, J., and W. J. Shu, 2008: Observation and analysis of nocturnal low-level jet characteristics over Beijing in summer. Chinese Journal of Geophysics, 51(2), 360-368. (in Chinese)

Li, J., R. C. Yu, and T. J. Zhou, 2008a: Seasonal variation of the diurnal cycle of rainfall in the southern contiguous China. J. Climate, 21, 6036-6043.

Li, J., R. C. Yu, and J. J. Wang, 2008b: Diurnal variations of summer precipitation in Beijing. Chinese Science Bulletin, 53(12), 1933-1936.

Lin, X. C., and S. Q. Yu, 2005: Interdecadal changes of temperature in the Beijing region and its heat island effect. Chinese Journal of Geophysics, 48(1), 39-45. (in Chinese)

Lin, Z. G., 1995: Topography-Induced Precipitation Climatology. Science Press, Beijing, 407pp. (in Chinese)

Sun, J. S., 2005: A study of the basic features and mechanism of boundary layer Jet in Beijing area. Chinese J. Atmos. Sci., 29(3), 445-451. (in Chinese)

Sun, J. S., and W. J. Shu, 2007: The effect of urban heat island on winter and summer precipitation in Beijing region. Chinese J. Atmos. Sci., 31(2), 311-320. (in Chinese)

Sun, J. S., and B. Yang, 2008: Meso- $\beta$ scale torrential rain affected by topography and the urban circulation. Chinese J. Atmos. Sci., 32(6), 1352-1364. (in Chinese)

Wang, X. Q., Z. F. Wang, Y. B. Gong, and H. Guo, 2008a: Modulation of urban heat island circulation on mountain-plain wind in the Beijing area. Cli- matic and Environmental Research, 13(5), 639-644. (in Chinese)

Wang, X. Q., Z. F. Wang, Y. B. Qi, and H. Guo, 2008b: The effect of urban heat island on the distribution of winter precipitation in Beijing region. Science in China (D), 38(11), 1438-1442. (in Chinese)

Wang, X. R., W. G. Wang, H. Z. Liu, and H. Wang, 2008c: Beijing region precipitation feature and some statistics of relationship between it and SHWP. Plateau Meteorology, 27(4), 822-829. (in Chinese)

Wang, Y., and F. Hu, 2006: Variations of the urban heat island in summer of the recent 10 years over Beijing and its environment effect. Chinese Journal of Geophysics, 49(1), 61-68. (in Chinese)

Wu, Z. H., 1993: Climate analysis of summer short-period precipitation in Beijing-Tianjin-Hebei area. Scientia Atmospherica Sinica, 17(3), 268-273. (in Chinese)

Yin, S. Q., D. Chen, and Y. Xie, 2009: Diurnal variations of precipitation during the warm season over China. Int. J. Climatol., 29(8), 1154-1170, doi: 10.1002/joc. 1758 .

Yu, R. C., J. Li, and H. M. Chen, 2009: Diurnal variation of surface wind over central eastern China. Climate Dyn., 33, 1089-1097, doi: 10.1007/s00382-008-04783 .

Yu, R. C., T. J. Zhou, A. Y. Xiong, Y. J. Zhu, and J. $\mathrm{Li}, 2007 \mathrm{a}$ : Diurnal variations of summer precipitation over contiguous China. Geophys. Res. Lett., 34, L01704, doi: 10.1029/2006GL028129.

Yu, R. C., Y. P. Xu, T. J. Zhou, and J. Li, 2007b: Relation between rainfall duration and diurnal variation in the warm season precipitation over central eastern China. Geophys. Res. Lett., 34, L13703, doi: 10.1029/2007GL030315.

Zheng, S. Y., and S. H. Liu, 2008: Urbanization effect on climate in Beijing. Climatic and Environmental Research, 13(2), 123-133. (in Chinese)

Zhou, T. J., R. C. Yu, H. M. Chen, A. G. Dai, and Y. Pan, 2008: Summer precipitation frequency, intensity, and diurnal cycle over China: A comparison of satellite data with rain gauge observations. J. Climate, 21(16), 3997-4010. 